\title{
Technology implementation in delivery of healthcare to older people: how can the least voiced in society be heard?
}

\author{
Yvonne van Zaalen, Mary McDonnell, Barbara Mikołajczyk, Sandra Buttigieg, \\ Maria del Carmen Requena and Fred Holtkamp
}

Information about the authors can be found at the end of this article.

Received 11 October 2017 Revised 19 March 2018 Accepted 19 March 2018

(c) Yvonne van Zaalen, Mary McDonnell, Barbara Mikołajczyk, Sandra Buttigieg, Maria del Carmen Requena and Fred Holtkamp. Published by Emerald Publishing Limited. This article is published under the Creative Commons Attribution (CC BY 4.0) licence. Anyone may reproduce, distribute, translate and create derivative works of this article (for both commercial and non-commercial purposes), subject to full attribution to the original publication and authors. The full terms of this licence may be seen at http://creativecommons.org/ licences/by/4.0/legalcode

This research was funded as part of the SIA RAAK MKB Project 2015-02-24M, Smart Care Homes and Assistive Technologies (SCHAT). The authors would like to acknowledge networking support by the COST Action IS1402 Ageism - a multi-national, interdisciplinary perspective.

\begin{abstract}
Purpose - The purpose of this paper is to focus on ethical and judicial themes related to technology and the older adults.

Design/methodology/approach - Different consecutive phases in technology design and allocation will be discussed from a range of perspectives.

Findings - Longevity is one of the greatest achievements of contemporary science and a result of development of social relations. Currently, various non-communicable diseases affect older adults and impose the greatest burden on global health. There is a great emphasis across Europe on caring for the older person in their own homes. Technology has a mediating role in determining the possibilities for good quality of life (QOL). The concept of assisting the older adult through the use of technology so as to access healthcare services has enormous potential. Although the potential of technology in healthcare is widely recognised, technology use can have its downsides. Professionals need to be aware of the risks, namely, those related to the privacy of the older person, which may accompany technology use.

Research limitations/implications - By 2050, there will be more people aged over 65 than there are children. This phenomenon of global ageing constitutes a massive challenge in the area of health protection. Practical implications - Professionals need to be aware of the risks, for example, related to the privacy of the older person, that may accompany technology use.

Social implications - There is a great emphasis across Europe on caring for the older person in their own homes. Technology has a mediating role in determining the possibilities for QOL.

Originality/value - The concept of assisting the older adult through the use of technology to avail of healthcare has enormous potential. Assistive technology, social media use and augmentative and alternative communication can have a positive effect on the QOL of older people, as long as they are supported enough in use of these technologies. However, ethical and juridical considerations are at stake as well.
\end{abstract}

Keywords Technology, Design, Older adults, Judicial, Social connectedness, Ethical considerations Paper type Technical paper

\section{Introduction}

\subsection{Older adults: the least voiced in society}

In 2050, there will be more people aged over 65 than there are children, and more centennials than ever before in the world's history, with nearly 80 per cent living in the less developed regions in 2050 (Department of Economic and Social Affairs, Population Division, United Nations, 2015, p. 9). This phenomenon of global ageing constitutes a massive challenge in the area of health protection. The fact that people live longer does not mean that they spend their later years in good health. Another phenomenon gaining emphasis across Europe is caring for the older person in their own homes. The idea behind it is that they have an increased autonomy and quality of life (QOL) as opposed to living in a residential home (Boulanger and Deroussent, 2008). Although aging adults wish to live in their own homes for as long as possible, it is costly due to a 
dearth of medical and social infrastructures in place (Frossard, 1990). In the context of the well-being of older persons, promotion and protection of human rights becomes difficult due to social exclusion of senior citizens as persons with disabilities and/or the "poorest of the poor" (Gruskin and Dickens, 2006). Both phenomena are reasons why the human right to health of older persons, understood as the right to the highest attainable standard of health, has appeared on international agendas as one of the most current and complex issues of human rights law. Undoubtedly, there is a close link between international human rights law and ethics. They both operate at different levels, but their aims are convergent. Both aim to preserve human dignity, also in situations of illness, disability and at the last stages of human life. We will delve into the ethical and juridical issues related to allocation of technical solutions to cope with health burden in older people.

When discussing human rights, the issue of inalienable human dignity is usually considered. In general, at international forums, the notion of human dignity means the equal and inherent value of every human being, regardless of gender, race, nationality, origin, religion, political opinion, property status, sexual orientation and, certainly, age. This notion is usually recognised as a source of values and human rights, and as their axiological base. The concept of dignity generally enjoys common appreciation at the international level, but currently its contents are unclear and disputable. The question that rises is "to what extent can technology be helpful in maintaining human dignity in healthcare processes?" Before we will address this question, we will give an overview of possible technological solutions for older people to cope with health and social burden.

The remarkable and constantly progressive ageing of societies affects all the spheres of social life. They face a lot of challenges connected with the so-called silver economy, among others. However, the greatest expectations are aimed at the healthcare sector. The remarkable improvements in life expectancy over the past century have entailed a shift in the leading causes of disease and death. One hundred years ago, infants and children comprised the largest group of victims of infections and parasitic diseases. Currently, various non-communicable diseases affect older adults and impose the greatest burden on global health. For authorities and civil society, ageing poses an enormous challenge when treating/managing chronic and geriatric diseases, palliative and end of life care, effective assistance for carers, the promotion of health and well-being and ensuring the concept of positive ageing. Referring to these tasks is not just a moral duty of States, but relevant obligations in this field arise also from international law, and especially the law on international human rights (WHO, 2002, 2006). The latter guides the actions of governments and, to some extent, assumes an ethical role on an international forum where human rights and ethics are closely linked. The concept of ethics refers traditionally to relationships of individual health workers, researchers, organisations and institutions providing healthcare within a country. Instead, international human rights are addressed, obliging them to protect all human beings living within their jurisdiction (Gruskin et al., 2006), across contexts including in the area of health. The aim of this paper is to explore ethical and judicial themes related to healthcare technology and the older adults. In this opinion paper, we will focus on the possible benefits and risks of technology use in healthcare of older people about which we have personal thoughts and beliefs. Our goal is to persuade the reader that our position on this topic is a valid one. Therefore, we support our claims with facts, real-life examples or published research studies. Before we discuss ethical dilemmas related to different consecutive phases in technology allocation from a diversity of perspectives, three modes of technological solutions and their effects will be introduced.

\subsection{Use of technology to cope with health and social burden in older persons has enormous potential}

The older person is beginning to emerge as an important consumer in relation to technology and its use (Vroman et al., 2015). The concept of assisting the older adult through the use of technology to avail of healthcare has enormous potential. Boot et al. (2015) endorsed the social connectedness and importance of engaging with family and friends whereby information technology can be of huge assistance. The demographic shift caused by the worldwide growth of the older population coincides with the dramatically altering and redefining how people 
communicate and relate to each other. Where the empowered, computer-literate young public is exerting tremendous influence on healthcare delivery, this is not seen in the older population. For the older population, this technological revolution can widen the generational gap and exacerbate feelings of loneliness, depression and anxiety and contribute to adjustment disorders. However, several studies indicate that bringing information and communication technologies (ICTs) to the older persons can have a significant positive influence on this population (Marek van de Watering, 2008; Tse et al., 2008). Some authors have even presented it as the only possibility for alleviating isolation, loneliness and alienation in certain older groups (Cody et al.,1999; Karavidas et al., 2005). Concurrently, it is known that a group of older people is unable to follow this development, because of mental challenges, communication or language problems or problems in self-use of computers or medical devices (Curran et al., 2007).

Dementia, cerebro vascular accident (CVA) and stroke in older adults are three examples of significant public health burden and are mostly characterised by problems in physical and mental decline (Schwamm et al., 2017). Various technology interventions may reduce the impact of the disease burden, in that solutions are emerging that render healthcare delivery, as well as assistance with activities of daily living (ADL), more accessible and affordable. Technologies mainly assist in memory support, treatment, safety and security, training, care delivery and social interaction (Lorenz et al., 2017). The usefulness of technology becomes even more salient for older adults with widespread inequalities in access to care, in particular due to living in rural/ remote areas or to provider shortages.

While technologies are proving to be essential in modern times to ensure high-quality care and independent living in older people suffering from dementia, CVA and stroke, "solutions must be socio-technical (that is, technologies must be developed alongside the networked social relations that make them 'work') and pragmatically customised to meet people's unique and changing medical, personal, social and cultural needs" (Greenhalgh et al., 2015, p. 91).

Technology can also play a mediating role in determining the possibilities for a life of quality (Walker, 2005). QOL technologies for healthy older adults may delay or prevent disability, encourage new activities and interests, assist in developing communication channels, improve knowledge, uplift mood, and ensure psychological and emotional health Schulz et al. (2014). However, to be successfully adopted these QOL technologies must be uncomplicated to use, trustworthy, effective and personalised. Inventors need to take into consideration older peoples' attitudes towards these technologies while monitoring and evaluating their use for improvement recommendations to be made (Hawley-Hague et al., 2014).

Below we will discuss the potential and challenges of three different technological modes: assistive technology (AT), social media and augmentative and alternative communication (AAC).

1.2.1 Assistive technology. AT like video-monitoring, remote health monitoring, electronic sensors and equipment such as fall detectors, door monitors, pressure mats and smoke alarms can improve older people's safety, security and ability to cope at home (Miskelly, 2001). AT, including wheeled mobility devices, has a significant impact on the ability to achieve functional independence and reduces the need for human assistance in older adults with disabilities. But if AT is being used as a reason to save money and (human) resources rather than looking at the needs of individuals for support and care, this is, in our opinion morally and ethically questionable. In addition the possibility of persuasion or even coercion of an individual with cognitive impairment to accept some form of assistive device may be rather questionable. Looking at this from a technical perspective is opposed to a person-centred approach. Unfortunately, in spite of being the largest group of consumers for utilisation of wheeled mobility devices, standard guidelines are lacking for prescription of these devices for older adults (Laferrier et al., 2010). Older people face different challenges in relation to medical device use. The challenges include the social consequences and effect on self-esteem, a certain amount of embarrassment, that are a result of these devices entering their lives. This change in situation from non-user to user can also have implications on the home in which they live and the people they share their life with (Thomson et al., 2013). Users are required to make adjustments to the way they live in their own homes (Thomson et al., 2013). The spouse and user are required to share the same physical environment and the resultant consequences of noise and aesthetics with the spouse not directly

PAGE 78 JOURNAL OF ENABLING TECHNOLOGIES $\mid$ VOL. 12 NO. 22018 
benefiting from device use. The fact that some of these devices are used in the shared bedroom means that sleep can be disturbed or sleeping arrangements have to be altered (changing sides of the bed, sleeping in another room).

1.2.2 Social media. Freund and Baltes (2000) highlighted the importance of information technology providing stimulation and remediation for the older person and also enhancing their interpersonal and social environment (Fozard and Kearns, 2008). Caregivers also need support in this particular space and Blusi et al. (2015) showed that if internet supports were in place for caregivers in rural areas, it might assist in reducing their feelings of isolation when caring for their spouses (Torp et al., 2007). Social contact with other carers also provided support and less need for information about chronic illness and there was enormous value placed on sharing experiences (Torp et al., 2007). Integrated care needs to encompass the use of information technology and expand on the importance of social connectedness for the older person and their carer.

Social media may increase the older person's empowerment and their sense of self-efficacy (Barak et al., 2008). Román-García et al. (2016) clearly articulated the presence of ICTs that lead to the development of new forms of social, interactive and critical relationships. Those relationships for the older person diminish as the person ages and there is a direct connection between income brackets and the level of media skills (Román-García et al., 2016). Bandura (1986) reported about personal self-efficiency and Compeau et al. (1999) highlighted the idea of computer self-efficacy. This can be achieved by the older person gaining confidence in their ability to use information technology in a trusted and protected way. As Bobillier-Chaumon et al. (2013) demonstrated learning situations should be created that would emphasise the older person's skills and if they are not supported, encouraged and coached by their trainers, then they lose their confidence. All of the above are very interesting and make up for wonderful opportunities for the older person. However, the ethical dimensions need further exploration, e.g. who has access to these data and what actually happens to the information gleaned from the engagement of the older person using technology are important questions?

Different effects of social media use in older persons are discussed in the literature: increasing social connectedness and level of health information, increase of cognitive ability, as well as predictors of engagement in use, like internal motivation, social support, reduced loneliness and intergenerational communication. In the paragraphs below we will discuss these issues.

Vosner et al. reported that age, gender and education seemed to be important factors having a direct or indirect impact on the use of social online networks by active older participants. In their study on older adults and communication technology, Vroman et al. (2015) showed that the majority of participants used ICT to maintain family and social connections and to inform themselves about health and other routine matters. ICTs may play an instrumental role in social connectedness and assist the older person in engaging with both the residents and their families (Sorell and Draper, 2014; Bobillier-Chaumon et al., 2013).

Another positive effect mentioned by de Aguilar-Nascimento et al. (2010) in a group of older people an increase in cognitive ability was observed especially in the language and memory domains. This emphasises the importance of providing appropriate access for the older person to use the internet. It also echoes the work of Shapiro (2007); and Chu et al. (2009) also reported that when older people were taught how to use computers, they demonstrated a significant improvement in psychological aspects such as depression, loneliness and feelings of control. Social support through ICT can assist the older person when they encounter physical or engagement problems associated with ageing such as limited mobility (Owen et al., 2015; van Ingen et al., 2017). However, Culley et al. (2013) clearly showed in previous work that as age increases, activities with technology decreases, with the majority of participants using the internet to keep in touch with family and look up information pertaining to their health status. It is vital that as a society we use technology to assist in improving social connections and help to alleviate the level of loneliness the older person may experience. There are special needs of the older person, which need to be met with regard to the use of technology utilising an ethical framework to ensure that their connectedness with the outside world is maintained but not exploited in any way. In their 
study of a Dutch experiment in using ICT to overcome loneliness amongst older adults, Fokkema and Knipscheer (2007), reiterating work by Vroman et al. (2015), concluded that the greatest reduction in loneliness was amongst those who were more highly educated with e-mail assisting in social contact and improving self-confidence. Heo et al. (2015) showed that higher levels of internet use was associated with higher levels of social support, reduced loneliness and a better QOL for the older person. Hill et al. (2015) also showed that the use of technology by older adults can assist in empowering themselves, thus contributing to a better QOL with Almeida et al. (2012) showed that older men who use computers have a lower risk of dementia, in their study of 5,506 community dwelling men aged between 69 and 87 years.

Olphert and Damodaran (2013) reiterated that if older people are digitally included, this results in them having better QOL, maintain their independence, improving their social connectedness and sense of worth despite declining health or limited capabilities. It is not enough just to have someone online, they need to be assisted in overcoming their vulnerability on the internet. This is where the ethics of use comes in and safe guards must be in place to protect the older person. Olphert and Damodaran (2013) recognised that this divide has implications for social inclusion. Morrison (2015) highlighted the importance of educating the older person in searching behaviour and effective training so that they protect themselves from the dangers of the internet. Maintaining meaningful social relationships is one of the key elements of ageing well (Leist, 2013). It is important to remember that with the rise of social media, as echoed by Leist (2013), new threats emerge for older adults. As the internet is a very valuable tool in reducing loneliness and isolation it is vital that we embrace its full use, whilst protecting the older person (Nyman and Isaksson, 2015). Nef et al. (2013) demonstrated that the main benefit of using social media for older adults is to enter the intergenerational communication, but privacy concerns and the ethical dimension of protecting the older vulnerable adult are a challenge.

1.2.3 Augmentative and alternative communication (AAC). AAC is a technological solution to cope with communication problems in older people. People who have acquired speech or language problems after brain trauma, CVA or dementia can benefit from AAC. It is easy to imagine that dysfunctional interaction patterns place older adults at risk for an impoverished QOL, the nursing staff at risk for a variety of physical and psychiatric health effects and burnout and the spouses at risk of feeling left out or powerless. Using AAC aids increases the number of "self"-positive conversational statements with a reduction in negative, ambiguous and repetitive utterances. Without AAC, nursing aides are likely to misinterpret residents' verbally disruptive and abusive behaviours, under the chronic strain of caring for frail elders with physical and mental impairments, and respond in ways that inadvertently reinforce residents' dependent behaviours, or may even result in abuse or neglect (Bourgeois et al., 2001).

Communication between nursing home residents with dementia and staff has been a long-standing problem that can have devastating ramifications for residents and staff alike (Bourgeois et al., 2001). Nursing home residents, often presumed to be incompetent and dependent by their caregivers, may be spoken to in stereotyped ways that limit their "chances for a meaningful conversation and convey a sense of declining capability, loss of control, and helplessness" (Ryan et al., 1995, p. 23). AAC memory tools seem to help participants to focus their attention on relevant personal information, allowing them to centre the conversation on core positive identity contents, thus improving the quality of the conversations with fewer ambiguous utterances (Gómez Taibo et al., 2014).

Although technological modes like AT, social media and AAC can have positive effects on the QOL of older people, ethical and juridical considerations are at stake as well. This is especially true in using medical devices. In the next chapter, we will discuss ethical and juridical issues related to all four phases of medical device allocation.

\section{Allocation process of technological medical devices}

The process of medical device allocation and the perspective of the user describe the chain of activities in the area of medical devices: from the moment, a problem is reported by the client, to

PAGE 80 J JOURNAL OF ENABLING TECHNOLOGIES $\mid$ VOL. 12 NO. 22018 
the evaluation in using the medical device that has been supplied (Nictiz, 2009). In Figure 1, the activities have been grouped as client actions and care expert actions. The regulatory frameworks within which the actions are performed are indicated for each activity. In the process of device allocation and use, four main phases can be distinguished: demand for care; assessment; allocation and use and evaluation. In every phase, decisions are made and ethical and juridical issues are considered. We will discuss them phase by phase.

\subsection{Phase 1: demand for care}

When a person or the caregiver realises that a problem exists and that an aid can be used as a compensation for the experienced limitations, he/she will get in contact with a healthcare professional. Before contacting the professional, this person has gone through a process of realisation of the loss of skills/abilities and the need for support or possible solutions. During the assessment phase the professional will formulate the demand for care based on the experienced limitations and the barriers in social life.

Although people share the same limitations on the level of activity, the impact of these limitations on participation in society can be completely different. Insight in personal demands, needs and wishes is essential in this phase. Therefore, the input in this phase is mainly given by the user resulting in ethical considerations for the professional that are mainly focussed on dignity, confidentiality and respect. To illustrate we give a real-life example, see Case 1.

2.1.1 Case 1. Robert is a 72-year-old retired policeman. After retirement, he remained active as a volunteer in a child protection home. Robert has diabetes Type 2. Due to the diabetes, the blood vessels of his left leg were affected to the level that a below knee amputation was executed. After the amputation, Robert's need for rehabilitation was high. The resistance felt in Robert's participation in the rehabilitation clinic was misinterpreted by the assigned care professional. The professional missed that Robert's main concern was: not to be able to walk around. The professional decided to talk with Robert's wife, without Robert knowing. He discussed the resistance to treatment with Robert's wife and asked her to convince Robert to be happy with

\section{Figure 1 The process of device allocation and the perspective of the user}

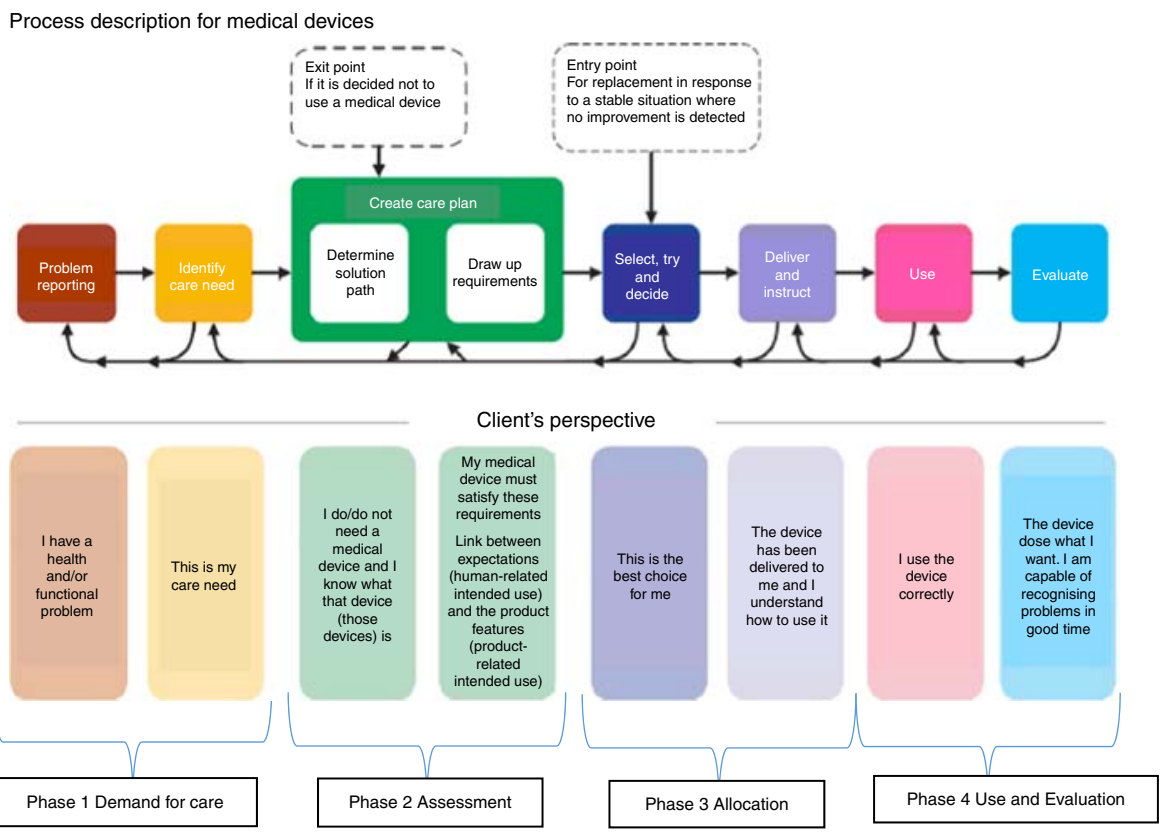

Source: Nictiz (2009) 
the offered care. Contrary to the professional's perspective, Robert wanted to remain an active member of society. In order to do that, he was not interested in exercises and acceptance of his limitations only. Robert needed mobility abilities within many different contexts as soon as possible. Temporary mobility solutions would have improved Robert's QOL.

Undoubtedly, the human right to health, which has been introduced into international law along with other rights referring to the existence of every human being (e.g. the right to life and the freedom from torture and inhuman or degrading treatment), is closely connected with human dignity. Growing old does not mean that a human being slowly loses his/her rights and/or his/her dignity shrinks. Unfortunately, very often getting old means to face more and more threats to human dignity, whether it is lack of access to healthcare, essential drugs and appropriate treatment, lack of privacy in hospitals and care institutions, treatment without the patient's consent, lack of personal data protection, or any number of other behaviours.

Confidentiality is one of the core duties of medical practice. It requires healthcare providers to keep a patient's personal health information private unless consent to release the information is given by the patient (De Bord et al., 2013). In situations like Robert's where a professional believes an ethical or legal exception to confidentiality exists, the question: will lack of this specific information put someone else at high risk of serious harm? should be asked. If the answer to this question is no, it is unlikely that an exception to confidentiality is ethically (or legally) warranted. The permissibility of breaching confidentiality depends on the details of each case. And if the person or someone else is at high risk of serious harm, breaching confidentiality may be required. But, with complex cases, health professionals are confronted with another dilemma regarding confidentiality, what do I need to share with another professional involved with, Robert? The fact that Robert is mostly interested in participating as a "healthy" citizen can be of great importance to the doctor who treats his diabetes as well. The only way to find out this answer is to ask Robert and follow his wishes, as long as this does not harm him.

In the interview with Robert the professional probably could have put more effort in trying to understand the reasoning of Robert with an open mind and at all times showing respect. But instead the professional decided, probably based on earlier experiences, that he knew without asking (i.e. tacit knowledge), and filled in the demand for care based on Robert's limitations. We argue that implicit handling based on tacit knowledge (Millar, 2008) is not evidence based, because the actions are unclear to all involved (Herbig et al., 2001; Verkerk et al., 2017). The International Classification of Functioning Disability and Health states that it is not the lack of activities or the severity of a handicap which should be paramount in assessment planning, but the participation question (World Health Organisation, 2009). In other words, the professional should have respected and asked for Robert's goals in life. Together with Robert he should have discussed the temporary and long-term demands and opportunities for Robert to get mobile again, before he even started his assessment.

\subsection{Phase 2: assessment}

The second phase of device allocation is mainly targeted on assessment and determination of the severity of limitations, possible compensations and design ideas. In this phase, ethical considerations are related to fiduciary trust; precise measurement; effective and confidential communication; age; personal preferences; and prejudice. Before a case study is introduced an elaboration on the topic of fiduciary trust will be made. Fiduciary derives from the Latin word for "confidence" or "trust". In these relationships, ethics demands a higher than ordinary degree of care and responsibility from the dominant or trusted party. The bond of trust between the patient and the professional forms the basis for an effective and efficient physician-patient relationship, based on honesty and forthrightness.

2.2.1 Case 2. Priscilla is an 81-year-old high class lady from Upper Manhattan, New York City. After she experienced a stroke, she developed global aphasia. She can produce few recognisable words and understand little or no spoken language. She can neither read nor write. Priscilla has fully preserved intellectual and cognitive capabilities unrelated to language and speech. During the assessment, the AT advisor on AAC aids decides that an AAC device is not 
applicable to this old lady. The advisor tells Priscilla that she should not worry anymore because he will take care of everything from now. Furthermore, he advises her children to draw pictures on a paper and invite Priscilla to do the same. As a result of this advice, Priscilla spends the last years of her life in total communicative silence.

During the assessment phase careful measurements, based on biomedical and psychosocial principles, should be made by an experienced and qualified professional. The professional must protect the subjects' privacy and confidentiality. Researchers must have mechanisms in place to prevent the disclosure of, or unauthorised access to, data that can be linked to a subject's individual identity. Second, in order for the care professional to make accurate diagnoses and provide optimal treatment recommendations, the patient must be able to communicate all relevant information about an illness or injury (Ludwig, 1998; De Bord et al., 2013). Professionals are obliged to refrain from divulging confidential information. This duty is based on accepted codes of professional ethics, which recognise the special nature of care professional-patient relationships.

Priscilla's severe communicative problems disturb the assessment phase dramatically. It takes a lot of time and skills by the assessor and advisor to detect the limitations and compensations of Priscilla. But in the above case the advisor is stressed in time and limited in effective communication, probably seriously affecting his decision making. Instead of searching for alternative communication modes and maybe influenced by prejudice about age he decides to advise on a communication mode that can contrast with her preferred life style.

Nursing staff extensively use elderspeak (infantilising communication) in conversations with older adults in long-term care settings, especially during care providing ADL (Williams et al. (2008). Piet Rijswijk (86), a retired teacher from Leusden, gave a clear example of this patronising behaviour when he told "the best example I can give you is when I was in the hospital and the nurse asked me if we were going to the loo together. I told her I preferred to do that on my own" (Wolthuis, 2013). In elderspeak, you underestimate other people. Research documents that elderspeak is perceived as patronising and can precipitate communication breakdown and problem behaviours for cognitively intact elders. In contrast, some social scientists promote the use of components of elderspeak to improve communication and cooperation in dementia care (Williams et al., 2008). The roles of stereotyping and stigmatisation need attention when a professional reflects on his/her behaviour. Older persons are a microcosm of the general population and individuals in their own right. Thus, the application of broad generalities is both dehumanising, inappropriate and even discriminatory in its origin. From an ethical point of view stigmatisation means less respect and a reduction in dignity.

The fact that Priscilla is 81 years of age and experiencing severe communication problems, does not say anything about her personal need to communicate in a delicate way. Especially because Priscilla used to talk to almost everyone she encountered in her life, before she got sick. It is possible that she is no longer capable of learning to communicate in a different way, because of age. However, a professional should not base his decisions on prejudice on assumed duration of use due to age or financial consequences of the allocation, only. In his Thematic Study, Grover, the UN Rapporteur on the right of everyone to the enjoyment of the highest attainable standard of physical and mental health, identified discrimination against older persons on the basis of their age as the major barrier to accessing primary care and preventing chronic illness. Grover noted that discriminatory attitudes of medical professionals towards older persons could also undermine meaningful communication with their patients, and as a result this might affect the accuracy of diagnosis and the quality of treatment. He calls upon everyone to respect the right to health by refraining from various discriminatory practices (UN General Assembly, 2011, paras 38-39, 57).

Professionals can ask themselves three questions: can this device serve as an effective compensator for this person in the next three to six months? Or, will this device fit the personal characteristics of the person? And, will this compensation fit within the context and activities of this person? And if an answer is not available, an initial try-out period could well help. But a question like: is this investment well made for a person this age? is not considered to be ethically correct. Cost-effectiveness analysis comparing alternative health interventions in the 
quality-adjusted life years produced from a given level of resources constitutes a quantitative method for prioritising different interventions to improve health. Ethical concerns regarding the applicability of cost-effectiveness and the quality-adjusted life years in regard to device allocation include: How is the value of a life defined? Should the young have a different access priority than the old? (3) How can we balance between the obligation to save a life and competing values? Six criteria have been proposed that should be met for QALYs to have ethical legitimacy in the clinical arena and within societal expectations. These include: QOL can be accurately measured and used; utilitarianism is acceptable; equity and efficiency are compatible; projections of community preferences can substitute for individual preferences; the old have less "capacity to benefit" than the young; and physicians will not use quality-adjusted life years as clinical maxims. Although these points are well-articulated and have some degree of rationality, they are not universally accepted. Ethical dilemmas ask for a thorough discussion, but straight forward or general answers are not easily apparent or provided.

Finally, the United Nations (2006b) also obliges States to take positive action in area of health protection. Its Article 25 requires taking all appropriate measures to ensure persons with disabilities to have access to health services that are gender sensitive, including health-related rehabilitation. "What is most important, older persons with disabilities are expressis verbis indicated as recipients of services designed to minimise and prevent further disabilities" (United Nations, 2006a).

When an advisor suggests a device, issues like personal preferences of the client on form, material and colour should be taken into account as far as reasonably possible. A fully effective device with an unwanted colour or fabric is less eligible for use, compared to an almost effective device with a preferred colour, design and or fabric. Use and satisfaction in particular are higher when the client is involved in the decision-making process on form, colour and fabric (Holtkamp et al., 2015). When a professional bases his ideas on his personal preferences or on commercial preferences that is considered to be unwanted and unethical behaviour. But when a professional works for a certain company which is not able to deliver a device but a competitive colleague is, we do understand that it can be difficult for that professional to advise on a device that he cannot sell. From an ethical point of view advisors about devices and allocators/producers of devices should make clear agreements to remain honest in their advice.

\subsection{Phase 3: allocation and delivering}

The third phase focusses on the manufacturing. The client expresses agreement to the choice of type of medical device or devices and investigates refund arrangements and procedures. The terms and conditions that apply to the provision of the medical devices are made clear to him. The professional determines which medical device(s) is (are) appropriate for the treatment goal and provides the desired level of function and inform the client of the pros and cons of this (these) medical device(s). He or she identifies contra-indications and consequences for the choice of medical device(s) and provides additional (written) information and gain client's consent for the care plan. Details are recorded in the care plan and the care expert will find out whether the client is aware that there may be financial consequences for him/her personally and provide guidance if required (Nictiz, 2009). The ethical dilemmas in this phase are related to the decisions made by the professional: conflicts of interest, carefulness, respectful handling, personal involvement, integrity and transparency (Nierse and van Zaalen, 2017; Vrieland and Elias, 2017).

2.3.1 Case 3. Based on a thorough assessment an advisor in medical devices comes to the conclusion that Roberta needs a communicative aid with certain operational characteristics. However, his company does not supply this particular device. He decides that his boss will not be happy if he advises Roberta to consult a competitor. He decides to advice a second-best device that can be delivered by his company.

Careful and respectful assessment, as is the case in Case 3, is preferable from an ethical point of view. In Case 3, the advisor has a dilemma, because he knows that he advises another device than the one which is, or could be the best compensatory solution for Roberta's problems.

PAGE 84 JOURNAL OF ENABLING TECHNOLOGIES $\mid$ VOL. 12 NO. 22018 
Advisors should never experience these conflicts of interest: what is the best for Roberta is not the best for his company's track record. After he realised that referring to a competitor was the best for Roberta and in the long run could result in recommendations to his firm, he realised that his future (and different) response will be different and beneficial for his company.

2.3.2 Case 4. Manuela has signed an agreement with her orthoptist that he would manufacture her foot orthosis with nylon, for reasons of flexibility of the material. But, when manufacturing Manuela's foot orthosis the orthoptist chooses to use polycarbonate, because the polycarbonate is available in their production unit and nylon is not.

In Case 4, two ethical borders are crossed. The orthoptist used material that has not been agreed on in the literature to be the golden standard for foot orthosis (polycarbonate is used in ankle foot orthosis) and he delivers something else than what is paid for. Without consulting Manuela, he did not follow the agreed plan. Although the orthoptist may have felt involvement in manufacturing the best orthosis, his level of integrity and transparency can be questioned, because he did not discuss the change of materials with Manuela.

\subsection{Phase 4: use and evaluation}

In the fourth phase, the device is delivered to the client and checked on the pre-determined characteristics. In this phase of the device allocation process evaluation, tuning and control of the usability and appropriateness of an aid is critically addressed. Many different ethical issues need considerations, like: ownership, safety, human contact replaced by a tool and device tracking. Devices should meet the criteria of the user/consumer but that does not mean that the issues related to safety can be left unattended. To illustrate the importance of safety in the process of device manufacturing have a look at Case 5.

2.4.1 Case 5. Edwin went to a shoe specialist to get new orthopaedic shoes. After a thorough assessment the device demands were clear and a beautiful set of boots was delivered. At home Edwin had severe difficulties walking the stairs. In fact, he fell on some steps a couple of times before he had the courage to call the orthopaedic shoe specialist. When he explained his usability problems the specialist realised that although he had done a careful assessment he had missed one, in this case very important, question "Are you wearing the boots in the house and outdoors?" The boots were stiff and inflexible, something that was very convenient in walking around the house, but incompatible with him walking the stairs.

In Case 5, the feeling of safety is discussed. The orthopaedic shoe specialist did a thorough assessment but he also assumed that Edwin would walk bare-footed in the house. This assumption is probably based on his own habits related to not wearing shoes in the house. Although something is normal to us, it is possible that people within another context, culture or religion have different habits. So we should never think that we know it all, and remain open-minded. Handling information exclusively based on tacit knowledge is seen as a shortcoming in the design process (Holtkamp et al., 2015).

In the above sections, ethical dilemmas were discussed in relation to clients and personal device allocations. But in particular older and people with severe health conditions move to homes for older people or nursing homes. Forgetfulness, negligence or messiness can result in losing devices. Losing items is a time-consuming occurrence in nursing homes that is poorly described. An exploratory study conducted by van Hoof et al. (2016) with 12 residents who had early-stage dementia and 12 family caregivers investigated which items got lost by nursing home residents, and how this affected the residents and family caregivers. The participants stated that numerous personal items and assistive devices got lost in the nursing home environment, which had various emotional, practical and financial implications. Significant amounts of time were spent in trying to find items. Numerous potential solutions were identified by the interviewees, among them was device tracking. Although that seems to be a solid and timesaving solution, it too has some ethical dilemmas.

2.4.2 Case 6. Milleny a 44-year-old women who lives in a nursing home suffers from both Multiple Sclerosis and mid-stage dementia. Because of her mobility problems the institution 
decided to provide Milleny with a walker-rollator so she would be able to walk around the nursing home when she wanted to. Due to her dementia on more and more occasions Milleny forgot where she had left her walking-rollator, resulting in frustration and despair. But Milleny was not the only resident of the nursing home who forgot where she left her medical devices. Walking-rollators, wheelchairs, beds and automated external defibrillator got lost in the nursing home. One of the professionals worried a lot about all the things that got lost and decided to observe people's behaviour during working hours. He knew almost everyone working and living in the nursing home, so he could easily observe them during working hours. After a while he noticed that Mr X was walking around with Milleny's walking-rollator. Mr X took the rollator into his living apartment in the nursing home. The professional kindly asked $\mathrm{Mr} \mathrm{X}$ to return the rollator and he did so. Everyone was happy. A couple of weeks, and many observations later, the professional went to ask the board members of the nursing home if a device track and trace system could be implemented in the nursing home to retrieve lost materials. The board members were hesitant and ask the medical ethical committee for advice.

In Case 6, two other main issues are at stake: professionalism and data tracking. First of all, the professional chooses to observe the behaviour of people present in the nursing home. These observations are not done within the job responsibilities of the professional, but it is particularly disturbing that he did not ask peoples' permission to be observed. By doing this he violates the principles of personal trust and safety of those people. Based on his observations he addresses $\mathrm{Mr}$ $X$ and points him at the missing walking-rollator. $\mathrm{Mr} X$ was probably unaware of his wrong doing and by addressing $\mathrm{Mr} X$ by a non-regular professional, $\mathrm{Mr} \mathrm{X}$ could feel worried, insecure and ashamed. The professional should have thought about this aspect of trust and safety before $\mathrm{Mr} X$ was addressed. The second dilemma in Case 6 concerns the data-tracking ideas. Although it sounds like a good solution the board members should realise that residents never opt into being tracked this way, as would be asked in mobile phone use, because they do not want it or do not directly benefit from it. If residents or consumers use products that belong to the institution, other ethical considerations should be made in tracking the devices compared to tracking products that are designed and/or owned by the person itself. When an older person uses products that belong to the institution, the institution often has the right to track this product, based on a signed user agreement. Tracking can also be defended if the person benefits from tracking the product himself. Conversely, so-called anonymous tracking is not very secure, because anonymity is fairly easily broken. Cracking open that anonymous shell/code and merging it with personally identifiable information from other sources is a fairly easy feat. In knowing where a product is at a certain moment and where it has been, a lot of information is gathered on the whereabouts of the user. The privacy of the residents in Case 6 , or of consumers in general, needs to be protected. Before a data-tracking device is installed consensus is needed on the location of data storage, data access and data security. Although information leakage is mostly not done on purpose: "I did not mean harm [...]", leaked information can be harmful for those involved.

\section{Conclusions}

The concept of assisting the older adult through the use of technology to avail of healthcare has enormous potential. AT, social media use and AAC can have a positive effect on the QOL of older people, as long as they are supported enough in use of these technologies. Although technological modes like AT, social media and AAC can have positive effects on the QOL of older people, ethical and juridical considerations are at stake as well. This is especially true in using medical devices. Ethical and legal considerations need to be made in the entire process of device allocation and evaluation. Ask yourself: what is a good response? But also ask yourself: What is certainly not a good response? Although lots of solutions are possible, the question is which solution or possibility is advisable. Even from within the standpoint of a particular ethical theory or ethical view, these issues' complexity means that different answers may be appropriate for a particular issue in the different contexts in which professionals work. Applying general statements implies substituting general terms for specific ones because a general descriptive statement applies to any arbitrary-specific case, instance or token. However, normative statements about actions are not applied in the same sense because individual cases of rational action are not arbitrary tokens.

\begin{tabular}{l|l|l} 
PAGE 86 & JOURNAL OF ENABLING TECHNOLOGIES & VOL. 12 NO. 22018
\end{tabular} 
For this reason, in normative contexts we may learn from a single example, which can be exemplary in a moral sense, without being an arbitrary sample. When applying normative good practice codes in care of older people, the derivation problem appears to occur in several ways and calls for careful meta-ethical reflection, prior to subsequent appropriate action.

\section{References}

Almeida, O.P., Yeap, B.B., Alfonso, H., Hankey, G.J., Flicker, L. and Norman, P.E. (2012), "Older men who use computers have lower risk of dementia”, PLoS One, Vol. 7 No. 8, pp. 1-6, doi: 10.1371/journal.pone.0044239.

Barak, A., Hen, L., Boniel-Nissim, M. and Shapira, N. (2008), "A comprehensive review and a meta-analysis of the effectiveness of internet-based psychotherapeutic interventions", Journal of Technology in Human Services 2008, Vol. 26 Nos 2/4, pp. 109-60.

Blusi, M., Kristiansen, L. and Jong, M. (2015), "Exploring the influence of internet-based caregiver support on experiences of isolation for older spouse caregivers in rural areas: a qualitative interview study", International Journal of Older People Nursing, Vol. 10 No. 3, pp. 211-20.

Bobillier-Chaumon, M., Michel, C., Tarpin-Bernard, F. and Croisile, B. (2013), "Can ICT improve the quality of life of elderly adults living in residential home care units? From actual impacts to hidden artefacts", Behaviour \& Information Technology, Vol. 33 No. 6, pp. 574-90.

Boulanger, J.R. and Deroussent, C. (2008), "Preliminary based service evaluation for elderly people and healthcare professionals in residential home care units", Second International Conference on the Digital Society, February, pp. 93-101.

Bourgeois, M.S., Dijkstra, K., Burgio, L. and Allen-Burge, R. (2001), "Memory aids as an augmentative and alternative communication strategy for nursing home residents with dementia", AAC Augmentative and Alternative Communication, Vol. 17, No. 3.

Bandura, A. (1986), Social Foundations of Thought and Action, Prentice Hall, Englewood Cliffs, NJ.

Boot, W.R., Charness, N., Czaja, S.J., Sharit, J., Rogers, W.A., Fisk, A.D., Mitzner, T., Lee, C.C. and Nair, S. (2015), "Computer proficiency questionnaire: assessing low and high computer proficient seniors", Gerontologist, Vol. 55 No. 3, pp. 404-11.

Chu, A., Huber, J., Mastel-Smith, B. and Cesario, S. (2009), “'Partnering with Seniors for Better Health': computer use and internet health information retrieval among older adults in a low socioeconomic community", Journal of the Medical Library Association, Vol. 97 No. 1, pp. 12-20.

Cody, M.J., Dunn, D., Hoppin, S. and Wendt, P. (1999), "Silver surfers: training and evaluating internet use among older adult learners”, Communication Education, Vol. 48 No. 4, pp. 269-86.

Compeau, D., Higgins, C.A. and Huff, S. (1999), "Social cognitive theory and individual reactions to computing technology: a longitudinal study”, MIS Quarterly, Vol. 23 No. 2, pp. 145-58.

Culley, J.M., Herman, J., Smith, D. and Tavakoli, A. (2013), "Effects of technology and connectedness on community-dwelling older adults", Online Journal of Nursing Informatics, Vol. 17 No. 3, p. 2864.

Curran, K., Walters, N. and Robinson, D. (2007), "Investigating the problems faced by older adults and people with disabilities in online environments", Behaviour \& Information Technology, Vol. 26 No. 6, pp. 447-53, doi: 10.1080/01449290600740868.

de Aguilar-Nascimento, J.E., Salomão, A.B., Caporossi, C. and Diniz, B.N. (2010), "Clinical benefits after the implementation of a multimodal perioperative protocol in elderly patients", Arquivos de Gastroenterologia, Vol. 47 No. 2, pp. 178-83.

De Bord, J., Burke, W. and Dudzinski, D.M. (2013), "Confidentiality ethics in medicine”, available at: https:// depts.washington.edu/bioethx/topics/confiden.html (accessed 4 April 2017).

Department of Economic and Social Affairs, Population Division, United Nations (2015), "World Population Ageing 2015 (ST/ESA/SER.A/390)".

Fokkema, T. and Knipscheer, K. (2007), "Escape loneliness by going digital: a quantitative and qualitative evaluation of a Dutch experiment in using ECT to overcome loneliness among older adults", Aging \& Mental Health, Vol. 11 No. 5, pp. 496-504.

Fozard, J.L. and Kearns, W.D. (2008), "Communication technology changes how we age gerontechnology", doi: 10.4017/gt.2008.07.02.043.00. 
Freund, A.M. and Baltes, P.B. (2000), "The orchestration of selection, optimization, and compensation: an action-theoretical conceptualization of a theory of developmental regulation", in Perrig, W.J. and Grob, A. (Eds), Control of Human Behaviour, Mental Processes and Consciousness, Erlbaum, Mahwah, NJ, pp. 35-58.

Frossard, M. (1990), "Hospital strategy and regional planning in France", The International Journal of Health Planning and Management, Vol. 5 No. 1, p. 59.

Gómez Taibo, M.L., Parga Amado, P., Canosa Domínguez, N., Vieiro Iglesias, P. and García Real, T. (2014), "Conversations about self-identity in Alzheimer disease: augmentative and alternative communication memory books as an aid", Revista de Logopedia, Foniatría y Audiología, Vol. 34 No. 2, pp. 60-7, available at: http://dx.doi.org/10.1016/j.rlfa.2013.04.008

Gruskin, S. and Dickens, B. (2006), "Human rights and ethics in public health", American Journal of Public Health, Vol. 96 No. 11, pp. 1903-05.

Greenhalgh, T., Procter, R., Wherton, J., Sugarhood, P., Hinder, S. and Rouncefield, M. (2015), "What is quality in assisted living technology? The ARCHIE framework for effective telehealth and telecare services", BMC Medicine, Vol. 13, p. 91, available at: http://doi.org/10.1186/s12916-015-0279-6

Hawley-Hague, H., Boulton, E., Hall, A., Pfeiffer, K. and Todd, C. (2014), "Older adults' perceptions of technologies aimed at falls prevention, detection or monitoring: a systematic review", International Journal of Medical Informatics, Vol. 83 No. 6, pp. 416-26.

Herbig, B., Büssing, A. and Ewert, T. (2001), "The role of tacit knowledge in the work context of nursing", Journal of Advanced Nursing, Vol. 34 No. 5, pp. 687-95.

Heo, J., Chun, S., Lee, S., Lee, K.H. and Kim, J. (2015), "Internet use and well-being in older adults", Cyberpsychology, Behavior, and Social Networking, Vol. 18 No. 5, pp. 268-72.

Hill, R., Betts, L.R. and Gardner, S.E. (2015), "Older adults' experiences and perceptions of digital technology: (dis)empowerment, wellbeing, and inclusion", Computers in Human Behavior, Vol. 48, pp. 415-23.

Holtkamp, F.C., Wouters, E.J.M., van Hoof, J., van Zaalen, Y. and Verkerk, M.J. (2015), "Use of and satisfaction with ankle foot orthoses", Clinical Research on Foot and Ankle, Vol. 3 pp. 810-4, doi: 10.4172/ 2329-910X.1000167.

Karavidas, M., Lim, N.K. and Katsikas, S.L. (2005), "The effects of computers on older adult users", Computers in Human Behavior, Vol. 21 No. 5, pp. 679-711.

Laferrier, J.Z., McFarland, L.V., Boninger, M.L., Cooper, R.A. and Reiber, G.E. (2010), "Wheeled mobility: factors influencing mobility and assistive technology in veterans and servicemembers with major traumatic limb loss from vietnam war and OIF/OEF conflicts", Journal of Rehabilitation Research and Development, Vol. 47 No. 4 , p. 349.

Leist, A.K. (2013), "Social media use of older adults: a mini-review”, Gerontology, Vol. 59 No. 4, pp. 378-84. Lorenz, K., Freddolino, P.P., Comas-Herrera, A., Knapp, M. and Damant, J. (2017), “Technology-based tools and services for people with dementia and carers: mapping technology onto the dementia care pathway", Dementia.

Ludwig, M.J. (1998), "Physician-patient relationship Ethics in Medicine".

Marek van de Watering (2008), available at: http://collab.ist.psu.edu/future-fall2008/team-space/life-longengagement/life-long-engagment-files/HCl_Essay_Marek_van_de_Watering.pdf

Miskelly, F.G. (2001), "Assistive technology in elderly care", Age Ageing, Vol. 30 No. 6, pp. 455-8, doi: 10.1093/ageing/30.6.455.

Millar, J. and Salt, J. (2008), "Portfolios of mobility: the movement of expertise in transnational corporations in two sectors - aerospace and extractive industries", Global Networks, Vol. 8 No. 1, pp. 25-50.

Morrison, R. (2015), "Silver surfers search for gold: a study into the online information-seeking skills of those over fifty”, Ageing International, Vol. 40 No. 3, pp. 300-10.

Nef, T., Ganea, R.L., Müri, R.M. and Mosimann, U.P. (2013), "Social networking sites and older users-a systematic review", International Psychogeriatrics, Vol. 25 No. 7, pp. 1041-53, doi: 10.1017/S1041610213000355.

Nictiz (2009), "Hulpmiddelenwijze", available at: www.cliq.nl (accessed 12 October 2009).

Nierse, C. and van Zaalen, Y. (2017), "De orientatiefase van praktijkgericht onderzoek", in Wouters, E. and Aarts, S. (Eds), Ethiek van praktijkgericht onderzoek. Zonder ethiek is het al moeilijk genoeg, ISBN 9789036817516, BSL, Baarn, pp. 27-34. 
Nyman, A. and Isaksson, G. (2015), "Togetherness in another way: internet as a tool for togetherness in everyday occupations among older adults", Scandinavian Journal of Occupational Therapy, Vol. 22 No. 5, pp. 387-93.

Olphert, W. and Damodaran, L. (2013), "Older people and digital disengagement: a fourth digital divide?", Gerontology, Vol. 59 No. 6, pp. 564-70.

Owen, J.E., Bantum, E.O., Gorlick, A. and Stanton, A.L. (2015), "Engagement with a social networking intervention for cancer-related distress", Annals of Behavioral Medicine, Vol. 49 No. 2, pp. 154-64.

Román-García, S., Almansa-Martínez, A. and Cruz-Díaz, M.-R. (2016), "Adults and elders and their use of ICTs”, Media Competence of Digital Immigrants, Vol. 24 No. 49, pp. 101-10.

Ryan, E.B., Meredith, S.D., MacLean, M.J. and Orange, J.B. (1995), "Changing the way we talk with elders: promoting health using the communication enhancement model", International Journal of Ageing and Human Development, Vol. 41 No. 2, pp. 87-105.

Schulz, R., Wahl, H.W., Matthews, J.T., De Vito Dabbs, A., Beach, S.R. and Czaja, S.J. (2014), "Advancing the aging and technology agenda in gerontology", The Gerontologist, Vol. 55 No. 5, pp. 724-34.

Schwamm, L.H., Chumbler, N., Brown, E., Fonarow, G.C., Berube, D., Nystrom, K. and Lacktman, N. (2017), "Recommendations for the implementation of telehealth in cardiovascular and stroke care: a policy statement from the American Heart Association", Circulation, Vol. 135 No. 7, pp. e24-44.

Shapiro, L. (2007), "The Embodied Cognition Research Programme", Philosophy Compass, pp. 338-46 No. 2, doi: 10.1111/j.1747-9991.2007.00064.x.

Sorell, T. and Draper, H. (2014), "Robot carers", Ethics and Older People, Vol. 16 No. 3, p. 183, doi: 10.1007/ si0676-01409344-7.

Thomson, R., Martin, J.L. and Sharples, S. (2013), "The psychosocial impact of home use medical devices on the lives of older people: a qualitative study", BMC Health Services Research, Vol. 13 No. 1, p. 467, available at: http://doi.org/10.1186/1472-6963-13-467

Torp, S., Hanson, E., Hauge, S., Ulstein, I. and Magnusson, L. (2007), "A pilot study of how information and communication technology may contribute to health promotion among elderly spousal carers in Norway: ICT and health among elderly spousal carers", Health \& Social Care in the Community, Vol. 16 No. 1, pp. 75-85, doi: 10.1111/j.1365-2524.2007.00725.x.

Tse, M.M., Choi, K.C. and Leung, R.S. (2008), "E-health for older people: the use of technology in health promotion", Cyberpsychology \& Behavior: The impact of the Internet, Multimedia and Virtual Reality on Behavior and Society, Vol. 11 No. 4, pp. 475-9.

UN General Assembly (2011), "Thematic study on the realization of the right to health of older persons by the Special Rapporteur on the right of everyone to the enjoyment of the highest attainable standard of physical and mental health, Anand Grover", General Assembly No. A/HRC/18/37, 4 July available at: www.un.org (accessed 19 March 2017).

United Nations (2006a), "Convention on the Rights of Persons with Disabilities of 13 December 2006", United Nations Treaty Series, Vol. 2515, p. 3, available at: www.treaties.un.org (accessed 19 March 2017).

United Nations (2006b), Convention on the Rights of Persons with Disabilities, United Nations, New York, NY, available at: www.un.org/disabilities/documents/convention/convoptprot-e.pdf (accessed 8 June 2017).

van Hoof, J., Douven, B., Janssen, B.M., Bosems, W.P.H., Oude Weernink, C.E. and Vossen, M.B. (2016), "Losing items in the psychogeriatric nursing home: the perspective of residents and their informal caregivers", Gerontology \& Geriatric Medicine, Vol. 2, pp. 1-9, doi: 10.1177/2333721416669895.

van Ingen, E., Rains, S.A. and Wright, K.B. (2017), "Does social network site use buffer against well-being loss when older adults face reduced functional ability?", Computers in Human Behavior, Vol. 70, pp. 168-77.

Verkerk, M.J., Holtkamp, F.C., Wouters, E. and Joost, H.V, (2017), "Mapping user activities and user environments during the client intake and examination phase: an exploratory study from the perspective of ankle foot orthosis users", Technology and Disability, Vol. 28 No. 4, pp. 148-57.

Vrieland and Elias (2017), "De uitvoeringsfase van praktijkgericht onderzoek", in Wouters, E. and Aarts, S. (Eds), Ethiek van praktijkgericht onderzoek. Zonder ethiek is het al moeilijk genoeg, ISBN 9789036817516 , BSL, pp. 27-34. 
Vroman, K.G., Arthanat, S. and Lysack, C. (2015), "'Who over 65 is online?' Older adults' dispositions toward information communication technology", Computers in Human Behavior, Vol. 43, pp. 156-66.

Walker, A. (2005), "A European perspective on quality of life in old age”, European Journal of Ageing, Vol. 2 No. 1, pp. 2-12.

WHO (2002), "World report on violence and health", WHO, Geneva, p. 126.

WHO (2006), "Global ageing report: threats to longevity - call for action", International Longevity Centre Global Alliance, November, Geneva, p. 10.

Williams, K.N., Herman, R., Gajewski, B. and Wilson, K. (2008), "Elderspeak communication: impact on dementia care", American Journal of Alzheimer's Disease and Other Dementias, Vol. 24 No. 1, pp. 11-20, doi: $10.1177 / 1533317508318472$.

Wolthuis, P. (2013), “Gaan we even een plasje doen”, Trouw, available at: www.trouw.nl/home/-gaan-weeven-een-plasje-doen- a0b4e318/ (accessed 31 March 2017).

World Health Organisation (2009), "Disability, a global picture", available at: www.who.int/disabilities/world_ report/2011/chapter2.pdf (accessed 24 June 2017).

\section{Further reading}

Robinson, H., MacDonald, B. and Broadbent, E. (2014), "The role of healthcare robots for older people at home: a review”, International Journal of Social Robotics, Vol. 6 No. 4, pp. 575-91.

Sposaro, F., Danielson, J. and Tyson, G. (2010), "iWander: an android application for dementia patients", The 2010 Annual Conference of the IEEE Engineering in Medicine and Biology Society (EMBC), Buenos Aires, pp. 3875-8.

van de Watering, M. (2008), "Lifelong engagemen”, available at: http://collab.ist.psu.edu/future-fall2008/ team-space/life-long-engagement/life-long-engagment-files/HCl_Essay_Marek_van_de_Watering.pdf (accessed 11 June 2015)

van Hoof, J. (2015), "Smart care homes and assistive technologies", RAAK MKB, Eindhoven.

Vošner, H.B., Bobek, S., Kokol, P. and Krečič, M.J. (2016), "Attitudes of active older internet users towards online social networking", Computers in Human Behavior, Vol. 55, pp. 230-41, doi: 10.1016/j.chb.2015.09.014.

\section{Author affiliations}

Yvonne van Zaalen is based at the Institute of Allied Health Professions, Fontys University of Applied Sciences, Eindhoven, The Netherlands.

Mary McDonnell is based at the Faculty of Science and Health of the Athlone Institute of Technology, Athlone, Ireland.

Barbara Mikołajczyk is based at the Faculty of Law and Administration, University of Silesia, Katowice, Poland.

Sandra Buttigieg is based at the Faculty of Health Sciences, University of Malta, Msida, Malta.

Maria del Carmen Requena is based at the Department of Psychology, Universidad de León, León, Spain.

Fred Holtkamp is based at the Institute of Allied Health Professions, Fontys University of Applied Sciences, Eindhoven, The Netherlands.

\section{Corresponding author}

Yvonne van Zaalen can be contacted at: y.vanzaalen@fontys.nl

For instructions on how to order reprints of this article, please visit our website:

www.emeraldgrouppublishing.com/licensing/reprints.htm

Or contact us for further details: permissions@emeraldinsight.com 